\title{
Conclusão: a sociedade e a natureza em questão
}

\author{
Fabíola Rohden
}

\section{SciELO Books / SciELO Livros / SciELO Libros}

ROHDEN, F. Conclusão: a sociedade e a natureza em questão. In.: A arte de enganar a natureza: contracepção, aborto e infanticídio no início do século XX [online]. Rio de Janeiro: Editora FIOCRUZ, 2003, pp. 219-224. História e saúde collection. ISBN: 978-65-5708-117-4. https://doi.org/10.7476/9786557081174.0009.

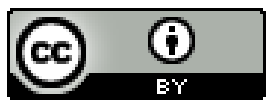

All the contents of this work, except where otherwise noted, is licensed under a Creative Commons Attribution 4.0 International license.

Todo o conteúdo deste trabalho, exceto quando houver ressalva, é publicado sob a licença Creative Commons Atribição 4.0.

Todo el contenido de esta obra, excepto donde se indique lo contrario, está bajo licencia de la licencia Creative Commons Reconocimento 4.0. 


\section{Conclusão:}

\section{a sociedade e a natureza em questão}

A questão do controle da natalidade se constitui em um problema social e político de grande importância sobretudo nas primeiras décadas do século XX, fenômeno presente no Brasil mas também nos Estados Unidos e países da Europa. O interesse particular da medicina a respeito da população que vem se intensificando desde o século anterior certamente é uma das facetas significativas desse processo. Esse interesse se expressa tanto na conformação de um 'pensamento social' médico quanto nas propostas de intervenção e, entre as suas principais características, pode-se destacar uma significativa valorização da maternidade e a condenação do controle da natalidade em prol do engrandecimento da nação e do futuro da espécie.

Esse tipo de proposição, tão paradigmaticamente explicitado na medicina, encontra-se presente em uma série de outros planos que também relacionam de alguma forma um determinado tipo de teoria social e política e as possibilidades de atuação do Estado. Entre esses planos se destaca o sistema jurídico-policial, que, por um lado, expressa muitas das idéias desenvolvidas inicialmente na medicina a respeito da questão da população e controle da natalidade e, por outro, é uma das instâncias que detém os poderes efetivos de regulação dos comportamentos individuais, através das sanções práticas àqueles e àquelas que praticaram atos considerados ilícitos.

Considerando esses dois focos de análise, pude descobrir um emaranhado de documentos que trazem à tona, de maneira bastante intrincada, discursos mais ou menos oficiais e normativos e indícios a respeito das práticas relativas ao comportamento sexual e reprodutivo das pessoas. Acredito que o contraponto entre o que dizia o pensamento médico e jurídico 
da época e aquilo que aparece, evidentemente já bastante filtrado, no âmbito dos inquéritos e processos permite que tenhamos alguma noção da complexidade que envolvia a questão da reprodução e do controle da natalidade. Por meio de exemplos, como o tratamento particular que é dado ao infanticídio - em virtude da incapacidade de se considerar que uma mãe possa por vontade própria suprimir a vida do filho -, a condenação do aborto provocado e do uso de contraceptivos e, em contraste, a valorização insistente da maternidade como a principal missão da mulher em eventos que envolviam médicos e estadistas, procurei mostrar como surge nesse momento toda uma configuração de idéias bastante particular. Uma configuração que está perfeitamente imersa no contexto de propostas e movimentos, distintos e variados, mas nem por isso desconectados, entre os quais é possível citar as preocupações com a conformação de um estado nacional, a ascensão da eugenia, a entrada mais significativa das mulheres no mercado de trabalho e as campanhas pelos direitos femininos que caracterizaram as primeiras décadas do século XX. De várias maneiras, todos esses movimentos traziam para o centro do palco a questão da população.

Diante das indicações que nos são fornecidas por esse quadro, uma questão relacionada ao estatuto do indivíduo diante da sociedade aparece de maneira insistente. Em vários momentos, vimos como se afirma que a mulher tem como obrigação primeira, senão única, 'dar um filho à sociedade'. Este é o laço primordial que a vincula à coletividade. Tudo o que se refere à sua capacidade reprodutiva não é algo que pertence exclusivamente ao domínio privado, individual - como poderíamos idealmente acreditar a partir de uma visão determinada pelas transformações autonomizantes que marcaram o período pós-1960 - mas se caracteriza como uma questão de interesse público, coletivo. É preciso esclarecer isso, pois é bastante evidente no teor dos documentos que o incentivo à maternidade não passa em primeiro plano pela realização de uma vontade individual, mas sim pela concretização das medidas que eram vistas como necessárias para que a nação se tornasse cada vez mais forte e populosa, dotada de cidadãos em número suficiente e com as 'qualidades' necessárias ao seu bom desenvolvimento.

Isso parece bastante curioso se consideramos que historicamente o domínio da sexualidade e da reprodução tem sido apontado como um dos importantes pilares da constituição do indivíduo moderno, autônomo e singularizado, processo tão amplamente descrito nas obras de autores como 
Michel Foucault, Louis Dumont ou Norbert Elias. É claro que esses autores também enfatizaram como a singularização caminha ao lado das formas de disciplina e controle, evidenciando a complexidade do processo. Contudo, o que na verdade parece intrigante nos casos descritos neste livro é que temos uma tensão entre a autonomização individual e a preeminência dada à sociedade.

O que se configura nas primeiras décadas do século XX é uma tentativa de regulação dos comportamentos no tocante a práticas relacionadas ao controle da natalidade que se caracteriza pela noção de educação das mulheres. É a partir do convencimento que a maternidade é defendida como a mais perfeita realização de suas vidas. O interessante é que, se estamos falando de educação ou convencimento, supõe-se que essas mulheres são dotadas de algum grau de autonomia, de vontade individual. São sujeitos com poder de decisão sobre os seus comportamentos e para os quais são planejadas campanhas de esclarecimento. Os eventos em prol da 'mulher-mãe' e da infância, que acontecem especialmente na era Vargas, tentavam difundir a noção da importância da maternidade para o bem da sociedade como um todo e tinham seus principais alicerces nos argumentos de cientistas, dentre os quais principalmente os médicos, que faziam os diagnósticos sobre o estado ainda problemático do país e os prognósticos sobre o seu possível grande futuro.

Ao mesmo tempo, a idéia de educação ou convencimento não deixa de refletir também uma certa 'tutelarização' dos indivíduos. As mulheres que tentavam controlar sua capacidade reprodutiva são descritas freqüentemente não como sujeitos plenos que por vontade própria tomam atitudes nesse sentido, mas como moral ou socialmente incapazes. No caso das infanticidas, por exemplo, o que se destaca é a perturbação dos sentidos e da inteligência provocada pelo parto, fator responsável pela realização de um ato de loucura. Já no que se refere ao aborto e ao uso de contraceptivos, não é possível deixar de notar que muitas vezes as mulheres são apresentadas como vítimas, seja dos 'praticantes inescrupulosos' ou então, de maneira mais indefinida, da 'civilização exagerada', dos 'costumes modernos'. Caberia, portanto, à medicina que estuda e trata e às instâncias do Estado que têm poder de regulação a tarefa de proteger as mulheres e a sociedade inteira desses males.

É notável que pareça estar sempre em jogo o bem-estar do coletivo, seja quando se fala em nome da nação ou quando se evoca a espécie 
humana, principalmente quando os debates são tingidos pelas cores da eugenia. As pessoas devem se comportar de determinada maneira em virtude do bem comum. No caso das mulheres, parece que este deve ser o único objetivo de suas vidas. Afirma-se que sua principal função é reproduzir, dar filhos à sociedade. Seus prazeres ou realizações individuais devem estar completamente subsumidos à sua missão mais ampla. Por isso o trabalho fora de casa ou a 'educação exagerada' são vistos como inadequados e mesmo prejudiciais. Em contraste com as mulheres que se lançam nos desafios do mundo do trabalho, que vivem sem pais ou maridos e, sobretudo, que não querem ter filhos - perfil que caracteriza várias personagens descritas nos inquéritos e processos analisados - se propõe o ideal da mulher altruísta. É preciso dizer que o caso dos homens não é tratado da mesma maneira que o das mulheres, tão amplamente tematizado por médicos, juristas e outros formadores de opinião. Parece evidente que têm uma série de outras funções sociais e que sua missão vai muito além da reprodução.

É preciso lembrar que a noção da mulher como inevitavelmente associada à maternidade envolve uma remissão à natureza. A natureza teria designado as mulheres à maternidade. Já aos homens, que têm uma fundamental mas rápida contribuição na reprodução, sobrariam todas as outras tarefas implicadas na sobrevivência. Além disso, outra equação natural é estabelecida entre o ato sexual e a conseqüente procriação. Os esforços empreendidos no sentido de rompimento dessas equações são percebidos com desconfiança.

É exatamente essa questão que está implícita na expressão que dá título a este livro: "a arte de enganar a natureza". Essa era uma das muitas maneiras de se falar da contracepção e do controle da natalidade já a partir do final do século XVIII. A natureza previa a associação imutável entre o sexo e a geração. As tentativas de interferência nesse processo são definidas - por aqueles que condenavam o sexo sem a reprodução - como meros engodos, iniciativas fadadas ao fracasso. A natureza, poderosa e superior, jamais seria ludibriada.

Porém, a despeito das suas opiniões, disseminava-se uma verdadeira 'arte', que compreendia os mais diferentes conhecimentos e artifícios de intervenção na relação entre sexo e reprodução. De fato, muitas vezes, a natureza acabava sendo mesmo 'enganada', para desgosto dos médicos e estadistas que defendiam o aumento da natalidade. Para estes, uma outra conseqüência associada a esse fato era que as mulheres vinham 
gradativamente se distanciando da sua capacidade natural para serem mães. Os 'avanços negativos da civilização' estariam levando as mulheres a abandonar os lares em favor do trabalho e da busca de autonomia, fazendo com que reprimissem os supostos instintos naturais. Em várias passagens, fala-se em reeducar as mulheres para que elas retornem à sua função natural de mães.

A maternidade é indiscutivelmente definida como natural. Recusase a pensá-la como um evento que é determinado por escolhas. Não se admite que entre o fato de engravidar e a concretização da maternidade como um evento dotado de amplo significado social há uma grande distância. É isto que está sendo mostrado pelas mulheres que buscam os meios contraceptivos ou tentam deter as gestações das mais variadas formas.

A recorrência da idéia de natureza chama a atenção para os significados mais amplos que as transformações no domínio da reprodução têm para a sociedade. A insistência com que a maternidade é definida como 'a' função natural da mulher nos leva a pensar sobre a importância da delimitação entre os domínios da natureza e da cultura. Definir o que é 'da natureza' implica, nesse contexto, definir também o que é considerado imutável. Em termos concretos, significaria dizer que as mulheres não poderiam jamais controlar o número de filhos tentando escapar dos desígnios naturais - o que, na prática, era feito das mais variadas formas, desde o uso de contraceptivos até o recurso ao aborto e ao infanticídio.

Dessa forma, tem-se também a reafirmação de uma determinada ordem social que se pauta pela rígida distinção das funções atribuídas a cada gênero. As conseqüências disso se traduzem não apenas nos modelos de comportamento sexual, reprodutivo e familiar, mas se articulam com desenvolvimentos mais amplos em termos econômicos, políticos e sociais. A visão a respeito da reprodução, que condiciona a mulher à maternidade, observada no material analisado, pode ser entendida como a expressão de um conjunto de regras sociais que não devem ser rompidas. Nos discursos analisados, idealmente, o mundo público deveria continuar sendo privilegiadamente um domínio masculino e o mundo privado, o lugar das mulheres, presas à manutenção da família e à criação dos filhos. Mas na prática não era bem assim. As iniciativas de entrada no mercado de trabalho, as tentativas de controle da natalidade e a luta por maior participação política indicavam que a fronteira imaginada - e desejada - entre esses dois mundos estava se corrompendo de uma maneira cada vez mais intensa. 
Na verdade, em termos concretos, ela nunca existira como algo estanque ou impermeável. Os fenômenos entendidos como pertencentes ao mundo público ou ao mundo privado sempre estiveram inevitavelmente relacionados, em uma dinâmica complexa e constante, apesar de insistentes tentativas de dicotomização.

A partir do tema da reprodução, freqüentemente associado apenas ao âmbito privado, procurei mostrar alguns fios que revelam como a articulação é imprescindível. O material produzido nos domínios da justiça e da medicina mostra que a reprodução e, sobretudo, o controle da natalidade são também assuntos do âmbito público e vistos como de importância política fundamental para o país naquele momento. Portanto, ao tratar desses temas, não estaríamos mais falando apenas da vida privada dos casais, mas da 'intimidade' da nação. 